\title{
Evaluating of the Outcomes of Median Nerve Decompression with a Mini Incision Proximal to the Distal Wrist Crease
}

\author{
Omer POLAT \\ Duzce University, Faculty of Medicine, Department of Neurosurgery, Duzce, Turkey \\ Corresponding author: Omer POLAT polatnrs@gmail.com
}

\section{ABSTRACT}

AIM: To evaluate the feasibility of the mini-open incision method in patients who underwent median nerve decompression in the carpal tunnel with a mini incision made proximal to the distal wrist crease.

MATERIAL and METHODS: A total of 80 patients ( 84 hands) operated by a single surgeon with a mini incision were included. The patients were evaluated postoperatively for the presence of pillar pain, pain on the incision scar, and scar sensitivity in addition to preoperative findings. The Quick Disabilities of the Arm, Shoulder and Hand (Quick DASH) questionnaire was used for clinical scoring. To evaluate the effectiveness of the method, the findings were recorded at and compared between at 12 and 24 months follow-ups.

RESULTS: No complications were observed at the wound site in the early postoperative period. Ten patients reported numbness, 5 experienced weakness, and 4 revealed positive Tinel's sign. Keloid formation without pain and scar sensitivity was detected in 2 patients at 6 months. No patient reported night pain, pain on pillar or incision scar, scar sensitivity, recent sensory loss, and disease recurrence. Numbness was present in 7 patients at 12 months and in 3 at 24 months; 3 and 2 patients reported weakness at 12 and 24 months, respectively. The mean Quick DASH score was 72.7 preoperatively, 10.2 at 12 months, and 9.1 at 24 months.

CONCLUSION: The median nerve decompression in the carpal tunnel may be performed with a mini incision made proximal to the distal wrist crease is effective and safe method, and provides less complications and higher patient comfort.

KEYWORDS: Carpal tunnel syndrome, Median nerve decompression, Mini incision

\section{INTRODUCTION}

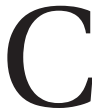
arpal tunnel syndrome (CTS) is the most common entrapment neuropathy and is caused by compression of the median nerve (MN) by the transverse carpal ligament within the carpal tunnel. CTS is mostly observed among women aged 30-60 years who use their hands frequently especially in the extension position (8). Surgical treatment is considered in cases with severe findings and in cases unresponsive to conservative approaches (8). Surgical treatment helps release the MN entrapped under the transverse carpal ligament within the carpal tunnel. Various surgical methods have been described in the literature for this purpose $(2,8,10,13)$.
The standard incision type made in classical open surgery extends between the distal end of the transverse carpal ligament and the proximal end of the palmar crest $(3,8)$. The standard surgical incision passing through the distal wrist crease is safe and provides complete exposure of the $\mathrm{MN}$ in the carpal tunnel. However, the scar tissue and scar sensitivity together with pillar pain and flexion contracture that may develop in the wrist can delay the complete functional recovery of the hand $(2,3,10)$. Thus, apart from the standard incision method, various surgical incision methods and endoscopic interventions have been described to promote early recovery of grip strength, reduce postoperative pain and localized tenderness, promote early return to daily live activities, and develop more esthetic scar tissue $(3,8,22)$. Although there are no electrophysiologically remarkable differences between the

Omer POLAT (10) : 0000-0003-4521-4312 
outcomes of these surgical methods, scar tissue formation at the incision site and pillar pain are the important factors affecting the success of the surgical method $(3,24)$. The miniopen carpal tunnel release surgery, which can be performed proximal or distal to the distal wrist crease, is a preferable method, however, the reliability of mini incisions is a matter of debate owing to disadvantages, such as limited surgical exposure, inadequate decompression, and nerve injury risk $(2,3)$.

The present study aimed to evaluate the reliability of the mini-open incision method in patients who underwent MN decompression in the carpal tunnel with a mini incision made proximal to the distal wrist crease. This study also determined the effects of the postoperative follow-up duration on postoperative outcomes.

\section{MATERIAL and METHODS}

This study was approved by the Duzce University Ethics Committee (Ref no: 2018/110). A total of 105 patients were operated by a single surgeon with a mini incision made proximal to the distal wrist crease owing to CTS between 2012 and 2017. Inclusion criteria were as follows: patients >20 years old, suspected CTS with pain, paresthesia and/or hypoesthesia in the area innervated by the $\mathrm{MN}$ with a duration of $>3$ months, electrophysiological confirmation of mild or moderate CTS (distal motor latency of $\geq 4.0 \mathrm{~ms}$ ), failure of conservative treatment $>3$ weeks and ability to complete the questionnaires.

The patients who had a history of previous surgery, wrist trauma and deformity, inflammatory arthropathy, underlying causes of CTS (e.g., diabetes mellitus, pregnancy), severe thenar muscle atrophy and signs or symptoms of disorders that could mimic CTS (e.g., cervical radiculopathy, polyneuropathy) were excluded.

Postoperative outcomes of 80 patients [72 (90\%) females, 8 (10\%) males; mean patient age, 56 (range, 35-70) years; total 84 hands] who regularly attended follow-up and final control visits were retrospectively evaluated.
Medical history and physical examination conducted preoperatively elicited night pain and numbness in the hands of all patients, weakness in $38(47.5 \%)$ patients, positive Tinel's test in 68 (85\%) patients (Table I). Surgical intervention was performed for the right wrists of $62(77.5 \%)$ patients, left wrists of $14(17.5 \%)$, and both wrists of $4(5 \%)$. Moreover, surgical intervention was performed on the dominant hand of $70(87.5 \%)$ patients.

\section{Surgical Method}

The surgical intervention was performed under local anesthesia without using a tourniquet or emptying arm veins via a pressure control system. While the patient was placed in the supine position with the hand, wrist and fingers stretched in slight extension position, a small silicon pillow was placed under the wrist. Local anesthetic ( $2 \%$ prilocaine hydrochloride, 7-10 cc) was superficially infiltrated stretching from the skin incision line on the distal wrist crease to the palm along the course of MN (Figure 1A). A 1.5-2 cm longitudinal incision, which was located on the vertical line drawn from the third interdigital space and extending proximally to the distal wrist crease, was performed. The skin-subcutaneous tissues were passed, the proximal end of the transverse carpal ligament was visualized, and the dorsal and ventral surfaces of the ligament were dissected with a dissecting clamp (Figure 1B). Using scissors, the transverse carpal ligament was cut on midline in the proximal to distal direction, not on the radial side to the third interdigital space so as to eliminate the risk of neurovascular iatrogenic injury, especially motor branches of the MN. The release of the MN in the carpal tunnel was confirmed using a dissector. Neurolysis was not performed in any of the patients. After achieving hemostasis, the surgical field was irrigated with a physiological saline solution and the skin was closed with a subcuticular suture (3/0 vicryl). The mean operation duration was average 12 (range, 10-15) minutes. The patients' hands and palms were dressed with ample cotton padding and were elevated. Splinting was not performed postoperatively in any patient. All patients were discharged on the same day, and peroral broad-spectrum antibiotic prophylaxis was administered for 48 hours. Active
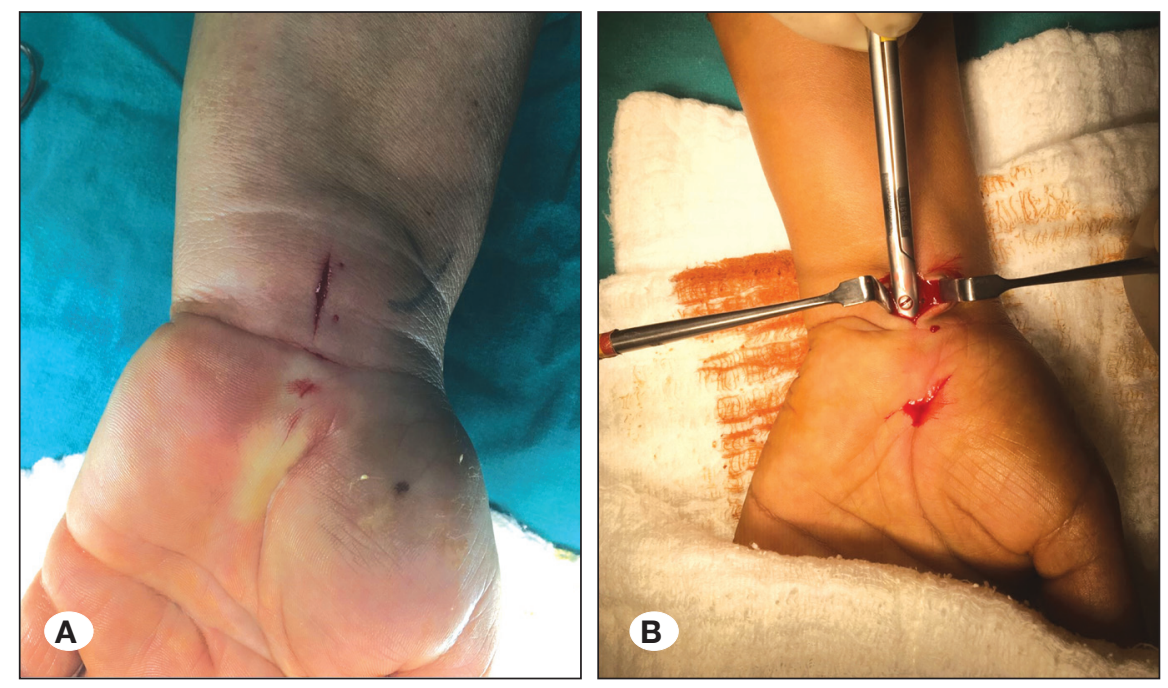

Figure 1: Intraoperative photographs. A) Superficial local anesthetic infiltration along the trajectory of the median nerve stretching to the palm and skin incision on the distal wrist crease. B) Sectioning of the dorsal and ventral surfaces of the ligament with the dissecting clamp. 
use of the hand was allowed from the postoperative $10^{\text {th }}$ day. The patients were scheduled to attend routine postoperative control visits at 3 and 6 weeks and at 3, 6, and 12 months and annually thereafter.

The patients were postoperatively questioned regarding night pain, numbness in the hand, weakness and Tinel's sign in addition to pillar pain, pain on the incision scar, and scar sensitivity. Moreover, the length of the scar tissue at the incision site was measured. Sensorial examination was performed to determine surgery-related sensorial deficits. The Quick Disabilities of the Arm, Shoulder and Hand (Quick DASH) questionnaire was used for preoperative clinical scoring and at the final control visits ( 0 , no disability; 100 , most severe disability) (9). The findings were recorded at and compared between at 12 and 24 months to evaluate the effectiveness of the method and determine whether the regression and improvement in the postoperative findings were related to the follow-up duration.

Data were analyzed using IBM SPSS (Statistical Package for Social Sciences for Mac ver.20; IBM Corp, Armonk, NY) software package. Continuous variables were expressed as mean and standard deviation, whereas categorical variables were expressed as percentage (\%). Paired sample t-test was used to compare continuous variables, and McNemar test was used to compare categorical variables. A p value of $<0.05$ was considered statistically significant.

\section{RESULTS}

No wound complications were observed in the first clinical evaluation performed at 3 weeks. The night pain was relieved in all patients at 6 weeks. Ten patients (12.5\%) reported numbness in the hand and 5 (6.25\%) experienced weakness. Moreover, the Tinel's sign was positive in 4 (5\%) patients (Table I). The mean length of the incision scar was $1.1 \pm 0.3$ (range, 0.7-1.5) cm (Figure 2A). No patient reported scar tissue formation at the incision site, pillar pain, or scar sensitivity. Keloid formation without pain and sensitivity was detected in 2 $(2.5 \%)$ patients at 6 months (Figure $2 B$ ). Sensorial examination in the early postoperative period elicited no new areas of numbness apart from those reported in the preoperative examination.

Evaluations performed at 12- and 24-months revealed no night pain, pillar pain, pain on the incision scar, scar sensitivity, new sensory loss, and recurrence in any of the patients. At both

Table I: Symptoms and Findings of Patients Preoperatively and at 6 Months Postoperatively

\begin{tabular}{lccc}
\hline & Preoperative & Postoperative 6 $^{\text {th }}$ months & \\
\hline Night pain & $\mathbf{n}(\%)$ & $\mathbf{n}(\%)$ & $\mathbf{p}$ \\
\hline Numbness & $80(100)$ & $0(0)$ & $<0.001$ \\
\hline Weakness & $80(100)$ & $10(12.5)$ & $<0.001$ \\
\hline Positive Tinel's test & $38(47.5)$ & $5(6.25)$ & $<0.001$ \\
\hline
\end{tabular}

n: Number of patients; expressed as percentages within parentheses. McNemar test was used to compare the data.

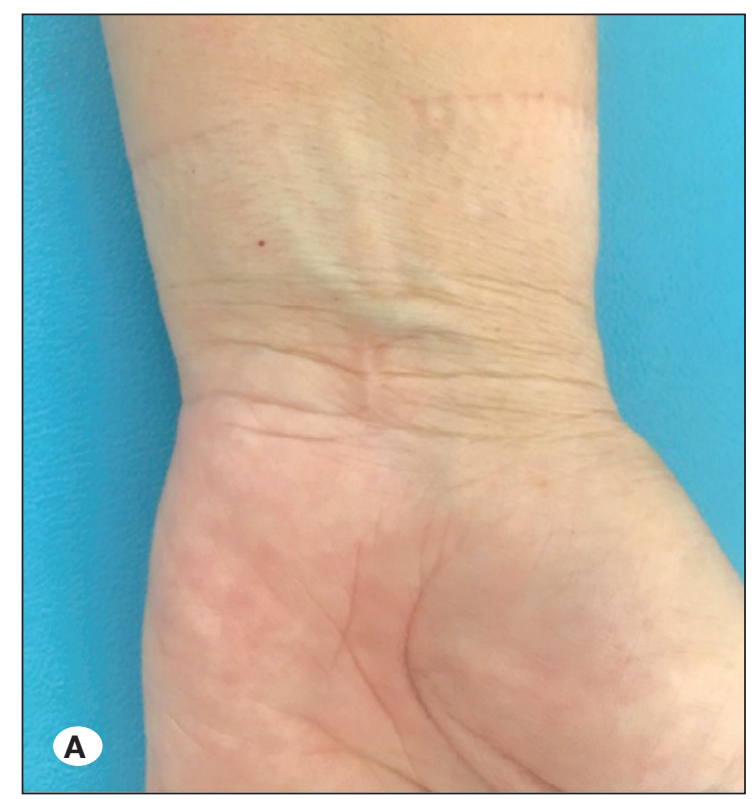

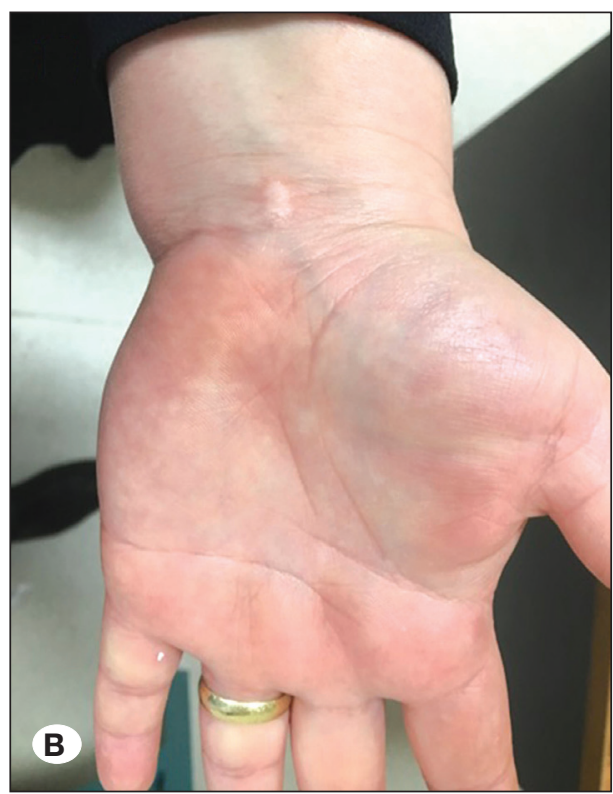

Figure 2: A) Incision scar. B) Patient in whom keloid formation was observed. 
Table II: Number of Patients and Clinical Scoring Results at 12- and 24-Month Control Visits according to the Postoperative Results

\begin{tabular}{lccc}
\hline & $\mathbf{1 2}^{\text {th }}$ months & $\mathbf{2 4}^{\text {th }}$ months & $\mathbf{n}$ \\
\hline Numbness in the hands & $\mathbf{n}$ & 3 & 0.06 \\
\hline Weakness & 7 & 2 & 1 \\
\hline Positive Tinel's test & 3 & 2 & 1 \\
\hline Keloid & 2 & 1 & 1 \\
\hline Ouick DASH scores* & 1 & $9.1 \pm 1.9(8-20)$ & 0.8 \\
\hline
\end{tabular}

$\boldsymbol{n}$ : Number of patients; expressed as percentage within parentheses. *Values are presented as mean \pm standard deviation and range within parentheses. McNemar test was used to compare categorical data. Paired sample t-test was used to compare the Quick DASH scores.

time points, the Tinel's sign was positive in $2(2.5 \%)$ patients. Numbness was reported by 7 (8.75\%) patients at 12 months and by $3(3.75 \%)$ at 24 months; moreover, $3(3.75 \%)$ and 2 (2.5\%) patients reported weakness at 12 and 24 months, respectively. The mean Quick DASH scores were $72.7 \pm 6.2$ (range, 65-80) preoperatively, $10.2 \pm 1.8$ (range, 9-22) at 12 months, and $9.1 \pm 1.9$ (range, $8-20$ ) at 24 months (Table II).

\section{DISCUSSION}

Standard open surgery is commonly used to treat CTS, however, there is a debate over the efficacy and reliability of this method $(7,14)$. Standard open surgery involving skin incisions extending to the proximal flexor wrist crease safely releases the $\mathrm{MN}$; however, it has certain disadvantages, such as pain and tenderness at the incision site, scar tissue formation, flexor contracture in the wrist, and weakening of grip and pinch strength $(3,7,14)$. These disadvantages have prompted researchers to seek new treatment options for CTS and mini-open surgical methods and endoscopic methods have been thus described $(3,11,21)$.

Complications related to scarring of the skin incision can be prevented in endoscopic carpal tunnel surgery. However, complication rates ranging from $2 \%$ to $35 \%$ related to this method have been reported in the literature $(19,20,23)$. These complications include neurovascular damage and tendon injuries, superficial palmar arc laceration, avulsion of the $\mathrm{MN}$, and recurrent CTS caused by incomplete sectioning of the transverse carpal ligament. Tuncay et al. reported that considering the potential of neurovascular damage, the open surgical approach should be used instead of endoscopic methods (23). Moreover, the technical learning curve of the endoscopic method is reportedly higher and this method is more expensive than open surgery $(1,3)$.

The mini-open method performed with palmar incisions in limited lengths decreases postoperative morbidities and accelerates the return to normal daily activities $(3,7,16)$. The use of mini-open methods for carpal tunnel surgery began with the mini-open two-incision method described by Biyani and Downes in 1993 (4), and the distal mini-open method described by Bromley in 1994 (5). Depending on the surgeons' experience and preference, mini incisions are performed in various ways, such as by transverse incisions parallel to the wrist crease, longitudinal incisions not passing the wrist crease, distal palmar incisions from the palmar region, and medial palmar incisions $(2,6)$. Nazzi et al. reported $90 \%$ remission in their patients who underwent various miniincision methods without endoscopy (18). Atici and Albayrak reported two separate groups of patients who were treated with incisions made either distal or proximal to the wrist crease (2); both incision methods were successful in terms of patient satisfaction, scar sensitivity, and night pain. Isik and Bostanci emphasized that a mini and single incision proximal to the wrist crease is a safe and effective surgical method (10). The use of mini incisions of limited length may also necessitate the use of specific surgical equipment. Specific knives (blades) developed for this purpose as well as tools, such as knifelight, help safely perform blind transverse carpal ligament release; however, using these is not always possible owing to accessibility and cost factors (3).

The results obtained from the present study conducted using a mini single incision proximal to the wrist crease corroborated with those of other studies reported in the literature. The main difference between our study and the others was that we evaluated and compared the postoperative findings at two different follow-up durations. The advantages of the surgical method reported in the present study include the lack of recurrence, rapid wound recovery, lack of pillar pain and scar sensitivity, and lack of restriction in grip function that poses a significant concern in palmar open surgery. Moreover, the high patient satisfaction and good long-term outcomes revealed in this study indicate that this method is safe and effective. The thin skin of the wrist facilitates surgical incision and suturing and prevents keloid formation and the associated scar sensitivity. The surgical incision made proximal to the distal wrist crease reduces the time required for wound healing and ensures a smaller incision as it is not located on a joint.

Because of the limited exposure, the canal and MN cannot be seen as widely as in the conventional procedure, and the major concern of the limited incisions has always been the risk of neurovascular iatrogenic injury. Variations of the $\mathrm{MN}$ in the carpal tunnel will be encountered in $3 \%-12 \%$ of cases (17). Examples are aberrations of the MN itself or its motor and palmar cutaneous branches and muscle/tendon anomalies. 
Among these, the more frequent ones are variations in the course of the recurrent thenar motor branch in relation to the flexor retinaculum (transligamentous $23 \%$, subligamentous $31 \%$, and extraligamentous $46 \%$ ), the different courses of the palmar cutaneous branch (15). An awareness of the variations in the pattern of the recurrent and palmar cutaneous branches of the $\mathrm{MN}$ is critical to avoid iatrogenic injury during miniincision CTS surgery. In the present surgical technique, it is crucial to make a cutting in the transverse carpal ligament on midline in the proximal to distal direction, not on the radial side to the third interdigital space so as to eliminate the risk of iatrogenic injury, because the motor branch is located radial to the third interdigital space line. Another complication that may be encountered when performing this surgical method is vascular injury that may occur when it is not felt that the distal edge of the ligament has been reached during blind sectioning of the transverse carpal ligament. There is no superiority of any technique, but because we cut the carpal ligament more medially, our rate of nerve injury due to variations is lower than that reported in the literature.

The method used in the present study was not compared with other surgical methods; this was one of the main limitations of the present study. Because this was not a comparative study, we could not make clear inferences regarding the superiority of the current method. Further, other than physical examination, we did not use any particular method to determine recurrence in the late postoperative period. Ultrasonography (USG) and EMG can help diagnose recurrence. USG is used to determine etiological factors in cases with recurrence. EMG is of little importance in the evaluation after carpal tunnel release surgery (12). Abnormal findings in the EMG examination can persist for months after a successful nerve release surgery. In some cases, electrophysiological evidence of recovery may not be observed despite achieving postoperative relief in clinical symptoms (12). Although many scoring systems are available for clinical evaluation, Quick DASH was used in our study owing to its superiority in terms of the ease of application and efficacy (25). The strength of the current study is that the reliability and efficacy of the surgical method was compared between two different evaluation time points in a homogeneous group of patients operated by a single surgeon.

\section{CONCLUSION}

The MN decompression in the carpal tunnel with a mini incision made proximal to the distal wrist crease is effective and safe and provides lesser complications and higher patient comfort. Surgical experience and taking anatomical variations of the nerve into account are essential to avoid the possible complications associated with the use of this method.

\section{REFERENCES}

1. Agee JM, McCarroll HR, Tortosa RD, Berry DA, Szabo RM, Peimer CA: Endoscopic release of the carpal tunnel: A randomized prospective multicenter study. J Hand Surg (Am) 17:987-995, 1992
2. Atıcı IBB, Albayrak S: Karpal tünel sendromu cerrahi tedavisinde pilla distalinden ve proksimalinden yapılan iki farklı mini insizyonun fonksiyonel sonuçlarının değerlendirilmesi. Türk Nöroşir Derg 24(3):275-279, 2014

3. Bal E, Piskin A, Ada S, Ademoglu Y, Toros T, Kayalar M: Comparison between two mini incision techniques utilized in carpal tunnel release. Acta Orthop Traumatol Turc 42(4):234237, 2008

4. Biyani A, Downes EM: An open twin incision technique of carpal tunnel compression with reduced incidence of scar tenderness. J Hand Surg Br 18:331-334, 1993

5. Bromley GS: Minimal-incision open carpal tunnel decompression. Hand Surg Am 19:119-120, 1994

6. Chen Y, Ji W, Li T, Cong X, Chen Z: The mini-incision technique for carpal-tunnel release using nasal instruments in Chinese patients. Medicine (Baltimore) 96:e7677, 2017

7. Cirpar M, Ari M, Turker M, Eksioglu FM, Cetik O: Karpal tünelin gevşetilmesinde sınırlı insizyon tekniğinin etkinliği ve güvenilirliği. Eklem Hastalık Cerrahisi 22(1):33-38, 2011

8. Gerritsen AA, Uitdehaag BM, van Geldere D, Scholten RJ, de Vet HC, Bouter LM: Systematic review of randomized clinical trials of surgical treatment for carpal tunnel syndrome. $\mathrm{Br} \mathrm{J}$ Surg 88:1285-1295, 2001

9. Hudak PL, Amadio PC, Bombardier C: Development of an upper extremity outcome measure: the DASH (disabilities of the arm, shoulder and hand) [corrected]. The Upper Extremity Collaborative Group (UECG) Am J Ind Med 29(6):602-698, 1996

10. Isik HS, Bostanci U: Experience of carpal tunnel syndrome that operated using a limited uni skin incision. Turk Neurosurg 21(2):177-180, 2011

11. Jimenez DF, Gibbs SR, Clapper AT: Endoscopic treatment of carpal tunnel syndrome: A critical review. J Neurosurg 88:817826, 1998

12. Karabay N, Toros T, Cetinkol E, Ada S: Correlations between ultrasonography findings and surgical findings in patients with refractory symptoms after primary surgical release for carpal tunnel syndrome. Acta Orthop Traumatol Turc 49(2):126-132, 2015

13. Keser N, Dortcan N, Cikla U, Uluc K, Celikoglu E, Is M, Gurer B: Semivertical incision: An aesthetically and electrophysiologically effective mini-incision technique for carpal tunnel decompression. Med Sci Monit 23:2993-3000, 2017

14. Kluge W, Simpson RG, Nicol AC: Late complications after open carpal tunnel decompression. J Hand Surg Br 21:205207, 1996

15. Kretschmer T, Antoniadis G, Richter HP, König RW: Avoiding iatrogenic nerve injury in endoscopic carpal tunnel release. Neurosurg Clin N Am 20:65-71, 2009

16. Lee WP, Strickland JW: Safe carpal tunnel release via a limited palmar incision. Plast Reconstr Surg 101:418-424, 1998

17. Lindley SG, Kleinert JM: Prevalence of anatomic variations encountered in elective carpal tunnel release. J Hand Surg (Am) 28(5):849-855, 2003 
18. Nazzi V, Franzini A, Messina G, Broggi G: Carpal Tunnel syndrome: Matching minimally invasive surgical techniques, Technical note. J Neurosurg 108:1033-1036, 2008

19. Palmer DH, Paulson JC, Lane-Larsen CL, Peulen VK, Olson JD: Endoscopic carpal tunnel release: A comparison of two techniques with open release. Arthroscopy 9:498-508, 1993

20. Skoff HD, Sklar R: Endoscopic median nerve decompression: Early experience. Plast Reconstr Surg 94:691-694, 1994

21. Tang CQY, Lai SWH, Tay SC: Long-term outcome of carpal tunnel release surgery in patients with severe carpal tunnel syndrome. Bone Joint J 99-B(10):1348-1353, 2017
22. Thoma A, Veltri K, Haines T, Duku E: A systematic review of reviews comparing the effectiveness of endoscopic and open carpal tunnel decompression. Plast Reconstr Surg 113:11841191, 2004

23. Tuncay I, Akpinar F, Tosun N, Vural S: Endoskopik karpal tünel gevşetme: Masum bir girişim mi? Acta Orthop Traumatol Turc 35:152-157, 2001

24. Wilson KM: Double incision open technique for carpal tunnel release: An alternative to endoscopic release. J Hand Surg Am 19(6):907-912, 1994

25. Yucel $H$, Seyithanoglu $H$ : Choosing the most efficacious scoring method for carpal tunnel syndrome. Acta Orthop Traumatol Turc 49(1):23-29, 2015 